\title{
A Rare Case Of Synchronous Multiple Primary Lung Cancer: Squamous Cell Cancer And Small Cell Lung Cancer
}

This article was published in the following Dove Press journal: OncoTargets and Therapy

\author{
Luxi Jiang' \\ Xiangxin Zheng ${ }^{2}$ \\ Shengchang $\mathrm{Wu}^{\prime}$ \\ Jie Zhang ${ }^{3}$ \\ Guoqing $\mathrm{Ru}^{4}$ \\ Yaqing $\mathrm{Li}^{1,5}$
}

'Department of Respiratory Medicine, Zhejiang Provincial People's Hospital, People's Hospital of Hangzhou Medical College, Hangzhou, Zhejiang 3100I4, People's Republic of China; ${ }^{2}$ Department of General Intensive Care Unit, the Second Affiliated Hospital, Zhejiang University School of Medicine, Hangzhou, Zhejiang 310052, People's Republic of China; ${ }^{3}$ Department of Rehabilitation Medicine, Zhejiang Provincial People's Hospital, People's Hospital of Hangzhou Medical College, Hangzhou, Zhejiang 3I00I4, People's Republic of China; ${ }^{4}$ Department of Pathology Zhejiang Provincial People's Hospital, People's Hospital of Hangzhou Medical College, Hangzhou, Zhejiang 3100I4, People's Republic of China; ${ }^{5}$ Key Laboratory of Tumor Molecular Diagnosis and Individualized Medicine of Zhejiang Province, Hangzhou, Zhejiang 3100I4, People's Republic of China
Correspondence: Yaqing $\mathrm{Li}$ Department of Respiratory Medicine, Zhejiang Provincial People's Hospital, People's Hospital of Hangzhou Medical College, 158 Shangtang Road, Hangzhou 3100 14, People's Republic of China Email lidoctor03@I26.com

\begin{abstract}
The incidence of synchronous multiple primary malignancies has been reported to be low. We report a rare case of synchronous lung squamous cell cancer and small cell lung cancer in an 82-year-old male patient. There is a lack of standard diagnostic criteria for multiple primary lung cancer. Two tumors with similar morphology are difficult to draw conclusions about the same lineage or different lineages. If the patient's physical condition permits, multiple tumors should be sampled and tested. Besides, imaging features are helpful for identification. It is advisable to diagnose synchronous multiple primary malignancies in an early stage, which contributes to a favorable outcome.
\end{abstract}

Keywords: synchronous multiple primary lung cancer, sMPLC, diagnosis, treatment

\section{Introduction}

Multiple primary lung cancer (MPLC) refers to the occurrence of two or more primary malignancies simultaneously or sequentially in the lungs of the same patient. ${ }^{1}$ The first cancer that occurs is called the primary cancer, and the subsequent occurrence is called repeat cancer. According to the time of tumor discovery, MPLC can be divided into $<6$ months of simultaneous MPLC (sMPLC) and $\geq 6$ months of metachronous MPLC (mMPLC).

The incidence of MPLC has been reported to range from $0.7 \%$ to $15 \%$ of patients with lung cancer. ${ }^{2-6}$ As reported in previous clinical series, the incidence rate of sMPLC varied from $0.2 \%$ to $8 \%{ }^{7}$ In China, this rate was $0.3 \%$ to $1.2 \%$ of patients with MPLC. 8,9 Among the 15,708 patients with primary lung cancer who underwent surgery from January 2004 to December 2012 in Shanghai Chest Hospital, 95 cases were MPLC, accounting for $0.60 \%(95 / 15,708)$, of which 46 cases were sMPLC $(0.29 \%)$ and 49 cases were mMPLC $(0.11 \%)$, consistent with the literature reports. ${ }^{10,11}$ sMPLC are rare, and the majority are of the same histologic type. Squamous cell cancer (SCC) and small cell lung cancer (SCLC) occur together extremely rarely. In one of the largest series of sMPLC, synchronous SCC and SCLC represented only $8.3 \%$ of these cases. ${ }^{12}$ We report a rare case of synchronous lung SCC and SCLC.

\section{Case Report}

An 82-year-old male patient was admitted to Zhejiang Provincial People's Hospital on 28 November 2017 after one-year-history of chest tightness and dyspnea. He 
was a farmer and has a sixty-year history of smoking with 30 cigarettes/d. Emergency chest CT examination showed that the left pulmonary hilum area was occupied $(4.1 \mathrm{~cm} \times 3.9 \mathrm{~cm})$ and malignant tumor was possible (Figure 1). The emergency CT examination also showed that the right adrenal was occupied. The staging for the tumor was deemed to be stage IV (T4N3M1b). Considering the old age of the patient, the family members of the patient refused further invasive examinations such as bronchoscopy and puncture biopsy and requested to return to the local hospital for treatment.

He was transferred to our hospital for further treatment on 15 May 2018, due to the aggravating shortness of breath and occasional cough. Laboratory examination revealed elevated tumor markers including CEA (5.2 ug/L), CA125 (221.5U/mL), NSE (83.8ng/mL), CYFRA211 (4.2ng/mL), ProGRP $(>5000 \mathrm{pg} / \mathrm{mL})$. The tumor marker SCC is normal $(1.4 \mathrm{ng} / \mathrm{mL})$. Blood cell counts showed white blood cells (WBC) $7.13 \times 109 / \mathrm{L}$, neutrophils $76.0 \%$, hemoglobin (Hb) $129 \mathrm{~g} / \mathrm{L}$, and platelet counts (PLT) $237 \times 109 / \mathrm{L}$. Autoimmune markers including anti-nuclear antibodies, rheumatoid factor and ANCA were negative. After admission, the chest CT was examined and a mass $(7.5 \mathrm{~cm} \times 6.7 \mathrm{~cm})$ was found in the left pulmonary hilum area, which was considered as malignant tumor and there were ground hyaline nodules in the lower lobe of the right lung (Figure 2).

Considering the possibility of lung cancer with lymph node metastasis, biopsy was suggested. The bronchoscopy examination showed new organisms of the left upper lobe and left lower superior segment obstructed bronchus (Figure 3a-3b). Biopsy of the lesion was performed for a histological and cytological examination. The remaining bronchi were passable, without pathology. Reviewing the chest CT images, we found that the mass in the left pulmonary hilum area is easy to see, but the mass in the left lower superior segment is difficult to distinguish, and whether two masses have the same histology is hard to differentiate on CT images. And this was also the reason why bronchoscopy was needed.

The pathological result of transbronchial lung biopsy was very interesting and immunohistochemistry results of two tumors were different. The left lower superior segment was SCC and it was positive for P40, P63, CK(Pan), and
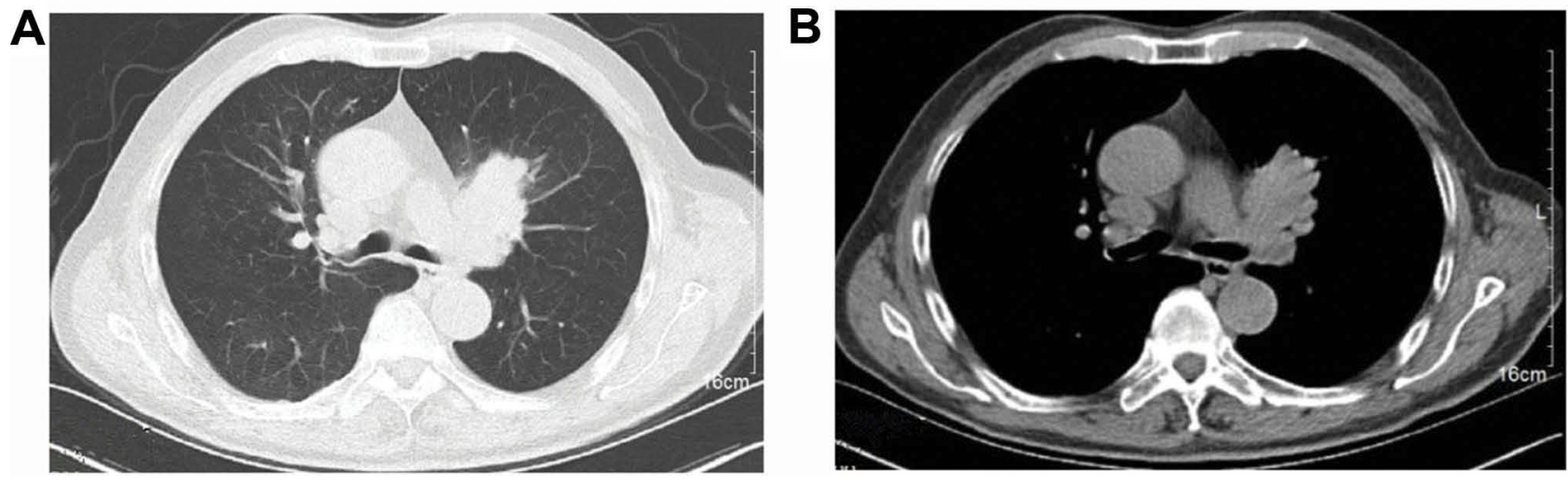

Figure I Chest CT scan (II.30.20I7) shows a $4.1 \times 3.9-\mathrm{cm}$ lung mass in the left pulmonary hilum area. (A) Lung window. (B) Mediastinal window.
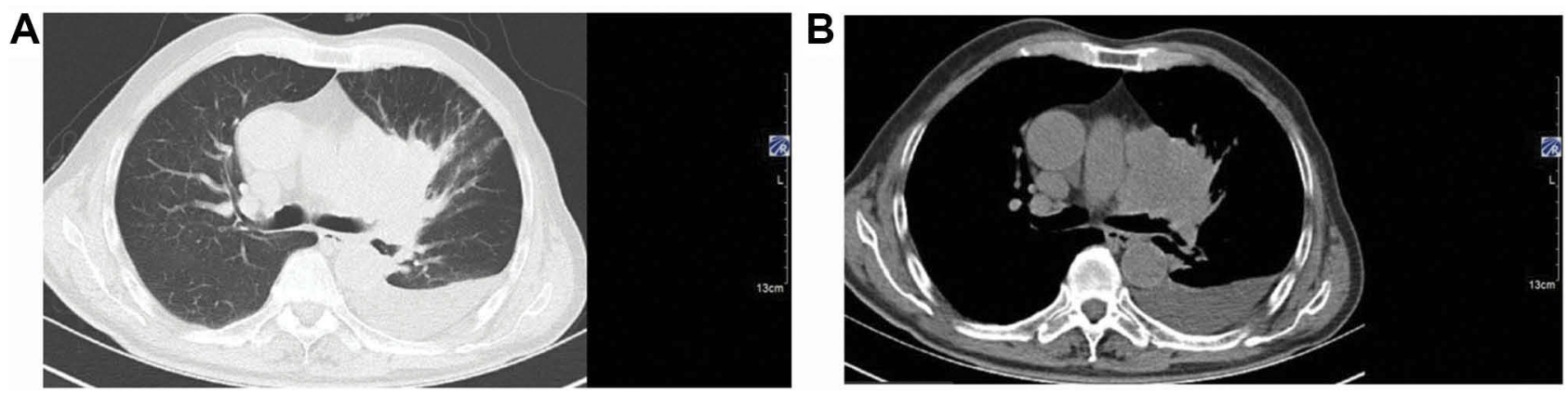

Figure 2 Chest CT scan $(05.16 .2018)$ shows a $7.5 \times 6.7-\mathrm{cm}$ lung mass in the left pulmonary hilum area. (A) Lung window. (B) Mediastinal window. 


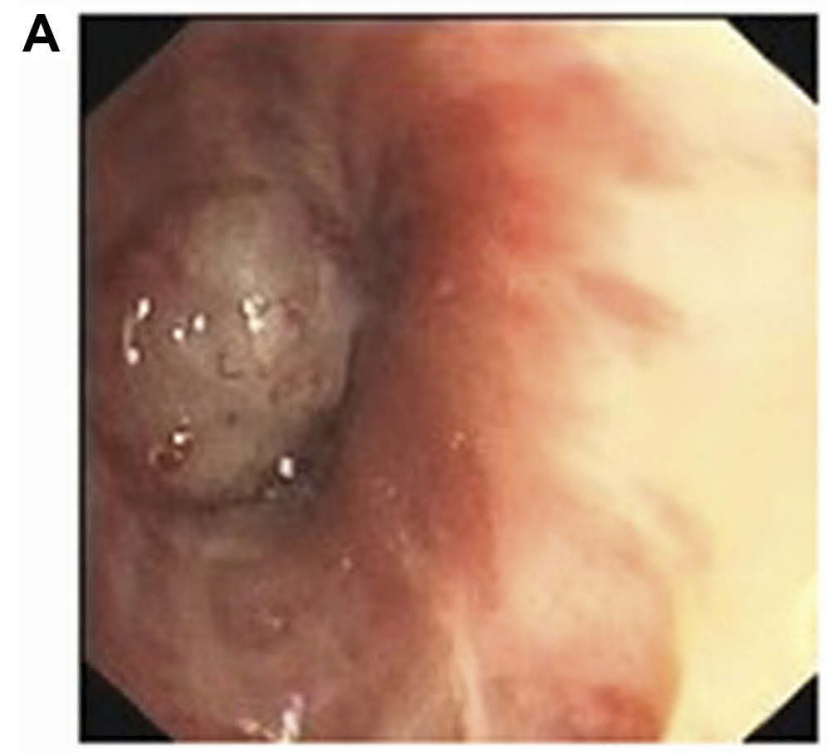

B

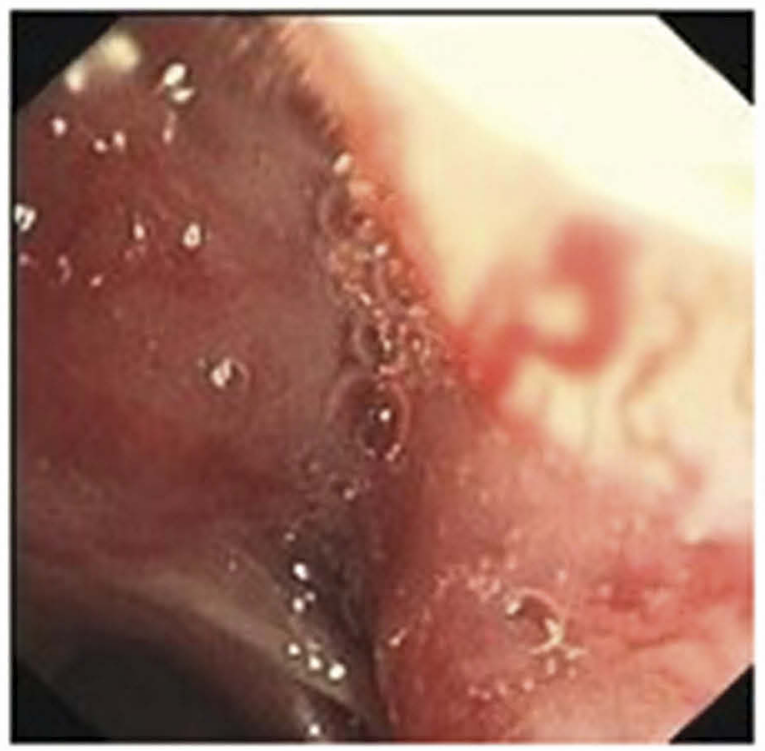

Figure 3 (A) The bronchoscopy examination showed tumor of the left lower superior segment obstructed bronchus. (B) Tumor of the left upper lobe obstructed bronchus.

negative for TTF-1, CK7, NapsinA. While the left upper lobe was SCLC and the tumor cells were positive for Ki67 (+80\%), CD117, CK(Pan), P53, CgA, CD56, TTF-1, SYN, and negative for LCA (Figure 4). Immunohistochemistry suggested that the tumor origins of the two sites were different and molecular profiles had significant heterogeneity. The final clinical diagnosis of this patient was SMPLC.

Besides, a right adrenal mass which is considered metastasis and abdominal lymph node metastasis were found in the CT examination. Therefore, the patient had contraindications of surgery. The patient has received systemic chemotherapy with carboplatin and etoposide. There are two recommended treatment options in NCCN guidelines for extensive small cell carcinoma. One is cisplatin combined with etoposide, and the other is carboplatin combined with etoposide. Since the patient was an 82year-old male, we chose carboplatin, which had little effect on renal function, rather than cisplatin.

\section{Follow-Up}

The reexamination of chest CT scan after two cycles of therapy showed that the mass in the left pulmonary hilum area $(7.1 \mathrm{~cm} \times 4.0 \mathrm{~cm})$ was smaller than the first admission (Figure 5) with stable disease (SD). After another two cycles of therapy, the chest CT scan showed that the left hilar mass $(7.1 \mathrm{~cm} \times 6.2 \mathrm{~cm})$ was larger than the last examination with progressive disease (PD) (Figure 6). The patient is still being followed up.

\section{Discussion}

In 1975, Martini and Melamed first proposed the diagnostic criteria for MPLC: The diagnosis of sMPLC needs to meet the following conditions: lung cancer occurs in different parts, isolated from each other, with different histological types; when the histological types are the same, they are located in different lung segments, lungs, different lateral lungs originated from different carcinomas in situ, and the common lymphatic drainage site of lung cancer had no cancer, and no extrapulmonary metastasis was established at the time of diagnosis. ${ }^{1}$ The current use in clinical research is still the Martini and Melamed standards. If morphological analysis provides differences between two tumors, it is relatively easy to determine that these pulmonary foci of cancer are separate primary tumors. In contrast to different morphological types, in the case of two tumors with similar morphology, a conclusion for the same lineage (primary tumor-metastases relation) or different lineage (two primary tumors) is not easy to reach. ${ }^{13}$ Demonstration of specific driver mutations by widely available PCR sequencing techniques may have use in establishing the lineage. ${ }^{14-17}$ Besides, imaging features listed below are helpful for identification. ${ }^{18}$ (1) MPLC's nodules have the characteristics of primary lung cancer: most of them have isolated round or round-shaped nodules, single nodules, lobulated sign, spiculated sign, unsmooth margins, ununiformed density, tracheobronchial stenosis and atelectasis. While metastatic cancer and 

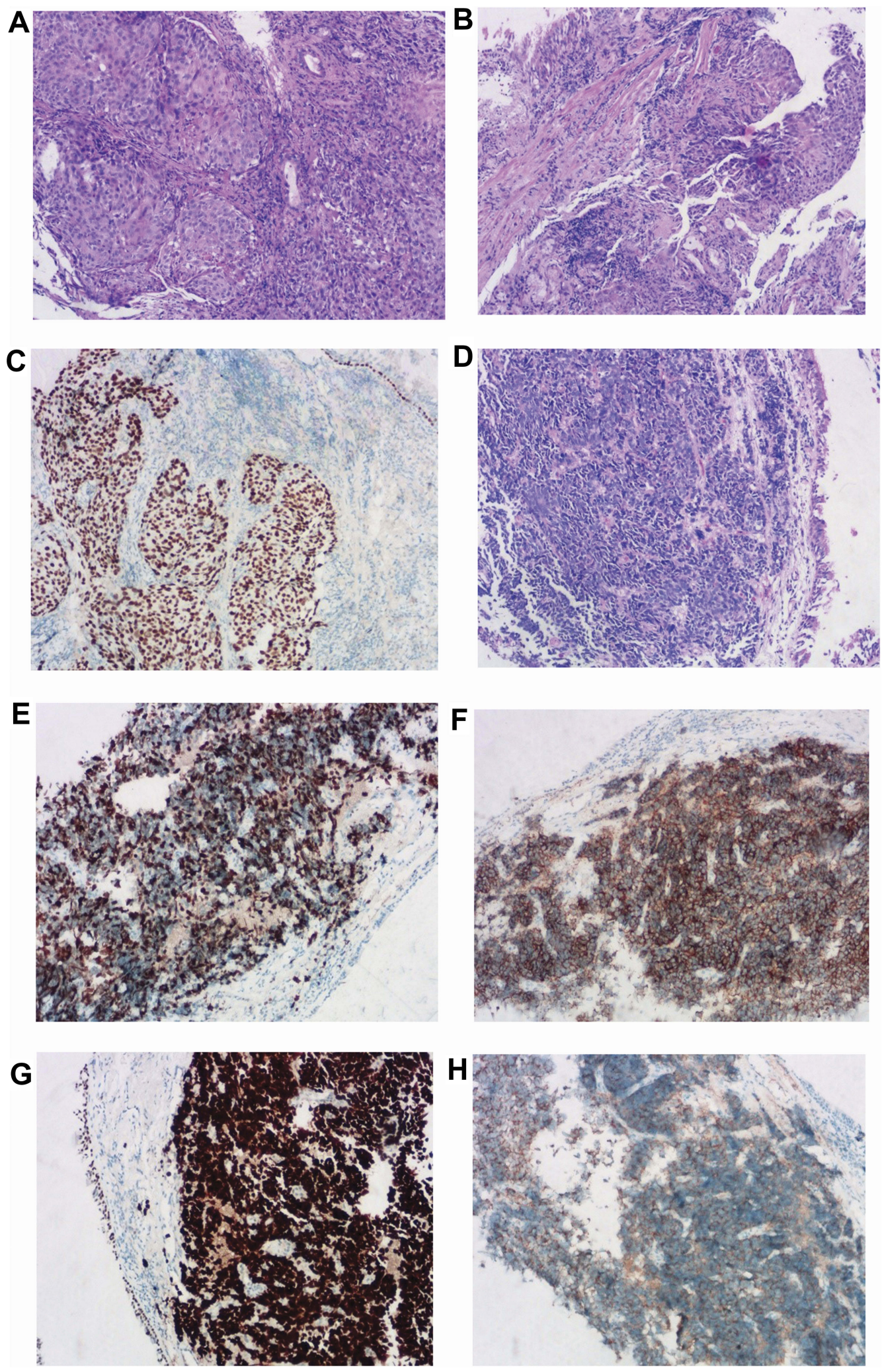

Figure 4 Immunohistochemical examination: (A, B) The left lower superior segment was squamous cell carcinoma and it was positive for (C)P40, P63, CK(Pan), negative for TTF-I, CK7, NapsinA. (D) The left upper lobe was small cell lung carcinomas and the tumor cells were positive for (E) Ki67(+80\%), CDII7, CK(Pan), P53, CgA, (F) CD56, (G) TTF-I, (H) SYN, and negative for LCA. 



Figure 5 Chest CT scan (08.22.2018) shows a $7.1 \times 4.0-\mathrm{cm}$ lung mass in the left pulmonary hilum area. (A) Lung window. (B) Mediastinal window.


Figure 6 Chest CT scan $(11.06 .2018)$ shows a $7.1 \times 6.2-\mathrm{cm}$ lung mass in the left pulmonary hilum area. (A) Lung window. (B) Mediastinal window.

recurrent cancer often have multiple spherical shadows, no lobulated and spiculated signs, smooth edges, uniform density, rarely produce atelectasis. (2) The primary cancer progresses more slowly and the patient's physical condition is good. While metastatic cancer and recurrent cancer progress faster, the patient is generally in poor condition. (3) The MPLC should be considered when both lungs have isolated masses, and no lymph node metastasis and distant metastasis appeared. In this case, the histological types of the two tumors were different, and the immunohistochemical analysis confirmed each diagnosis.

In this case, the final staging for the SCLC was deemed to be extensive and for the SCC to be stage IV. Due to the advanced stage of lung cancer, the patient lost the opportunity for surgery and we initiated chemotherapy for him. According to the recommendations of the reported studies, it is advisable to consider sMPLC as a local pathology and to perform radical surgical treatment, which contributes to a favorable outcome. ${ }^{19,20}$ So far, most of the sMPLC cases reported were in early stages with a good prognosis after surgery. The efficacy of chemotherapy for patients in advanced stage needs further research.

With the advancement of diagnostic techniques, screening of high-risk populations of lung cancer, the prolongation and close follow-up of postoperative survival rates of lung cancer patients, we hope that MPLC can be detected in an early stage with a good prognosis after surgery.

\section{Ethics}

This patient provided written informed consent for the publication of the case details and images. And ethical approval for this study was obtained from the meeting of ethics committee of Zhejiang Provincial People's Hospital.

\section{Acknowledgments}

This work was supported by grants from the National Natural Science Foundation of China (No. 81870028,81470241) and sponsored by Zhejiang Provincial Program for the Cultivation of High-level Innovative Health talents (No. A-2017CXCR02). 


\section{Disclosure}

The authors report no conflicts of interest in this work.

\section{References}

1. Martini N, Melamed MR. Multiple primary lung cancers. $J$ Thorac Cardiovasc Surg. 1975;70(4):606-612.

2. Ferguson MK, DeMeester TR, DesLauriers J, Little AG, Piraux M, Golomb H. Diagnosis and management of synchronous lung cancers. J Thorac Cardiovasc Surg. 1985;89(3):378-385.

3. Verhagen AF, van de Wal HJ, Cox AL, Lacquet LK. Surgical treatment of multiple primary lung cancers. Thorac Cardiovasc Surg. 1989;37(2):107-111. doi:10.1055/s-2007-1013919

4. Lam S, MacAulay C, Palcic B. Detection and localization of early lung cancer by imaging techniques. Chest. 1993;103(1 Suppl):12S14S. doi:10.1378/chest.103.1_supplement.12s

5. Woolner LB, Fontana RS, Cortese DA, et al. Roentgenographically occult lung cancer: pathologic findings and frequency of multicentricity during a 10-year period. Mayo Clin Proc. 1984;59(7):453-466. doi:10.1016/s0025-6196(12)60434-0

6. van Rens MT, Zanen P, Brutel de La Riviere A, Elbers HR, van Swieten HA, van Den Bosch JM. Survival in synchronous vs. single lung cancer: upstaging better reflects prognosis. Chest. 2000;118 (4):952-958. doi:10.1378/chest.118.4.952

7. Warth A, Macher-Goeppinger S, Muley T, et al.. Clonality of multifocal nonsmall cell lung cancer: implications for staging and therapy. Eur Respir J. 2012;39(6):1437-1442. doi:10.1183/09031936.00105911

8. Zhang LLW, Jiaan D, Wen G. Surgical treatment of multiple primary lung cancer. Chin J Thorac Cardiovasc Surg. 2004;20(1):59.

9. Wang Yonggang WL, Dechao Z, Rugang Z, Dawei Z. Diagnosis and surgical treatment of double primary lung cancer. Chin J Oncol. 2001;23(5):428-430.

10. Li X, Hemminki K. Familial multiple primary lung cancers: a population-based analysis from Sweden. Lung Cancer. 2005;47(3):301307. doi:10.1016/j.lungcan.2004.07.048
11. B S, Baan R, Grosse Y, et al.; WHO International Agency for Research on Cancer Monograph Working Group. A review of human carcinogens-part E: tobacco, areca nut, alcohol, coal smoke, and salted fish. Lancet Oncol. 2009;10(11):1033-1034.

12. Ghattas C, Hundal M, Agustin M, Unterborn J. A rare type of synchronous multiple primary lung cancer: staging and treatment dilemma. Am J Resp Crit Care. 2016;193:A6125.

13. Kozower BD, Larner JM, Detterbeck FC, Jones DR. Special treatment issues in non-small cell lung cancer: diagnosis and management of lung cancer, 3rd ed: American College of Chest Physicians evidence-based clinical practice guidelines. Chest. 2013;143(5 Suppl): e369S-e399S. doi:10.1378/chest.12-2362

14. Wu CT, Lin MW, Hsieh MS. Kuo SW, Chang YL. New aspects of the clinicopathology and genetic profile of metachronous multiple lung cancers. Ann Surg. 2014;259(5):1018-1024. doi:10.1097/SLA.0000 000000000385

15. van Rens MT, Eijken EJ, Elbers JR, Lammers JW, Tilanus MG, Slootweg PJ. p53 mutation analysis for definite diagnosis of multiple primary lung carcinoma. Cancer. 2002;94(1):188-196. doi:10.1002/ cncr.10001

16. Kadara H, Wistuba II. Field cancerization in non-small cell lung cancer: implications in disease pathogenesis. Proc Am Thorac Soc. 2012;9(2):38-42. doi:10.1513/pats.201201-004MS

17. Wang X, Wang M, MacLennan GT, et al. Evidence for common clonal origin of multifocal lung cancers. $J$ Natl Cancer Inst. 2009;101(8):560-570. doi:10.1093/jnci/djp054

18. Baohui. LYH. Progress of diagnosis and treatment for multiple primary lung cancer. Chin Clin Oncol. 2014;19(10):953-956.

19. Dai L, Yang HL, Yan WP, et al. The equivalent efficacy of multiple operations for multiple primary lung cancer and a single operation for single primary lung cancer. J Thorac Dis. 2016;8(5):855-861. doi:10.21037/jtd.2016.03.42

20. Zhang Z, Gao S, Mao Y, Mu J, Xue Q, Feng X, He J. Surgical outcomes of synchronous multiple primary non-small cell lung cancers. Sci Rep. 2016;6:23252. doi:10.1038/srep23252

\section{Publish your work in this journal}

OncoTargets and Therapy is an international, peer-reviewed, open access journal focusing on the pathological basis of all cancers, potential targets for therapy and treatment protocols employed to improve the management of cancer patients. The journal also focuses on the impact of management programs and new therapeutic agents and protocols on patient perspectives such as quality of life, adherence and satisfaction. The manuscript management system is completely online and includes a very quick and fair peer-review system, which is all easy to use. Visit http://www.dovepress.com/ testimonials.php to read real quotes from published authors. 